\title{
Correction to: An integrated approach of logistic-MCE-CA-Markov to predict the land use structure and their micro-spatial characteristics analysis in Wuhan metropolitan area, Central China
}

\author{
Quan Wang ${ }^{1} \cdot$ Haijun Wang ${ }^{1,2}$
}

Published online: 20 January 2022

๑) Springer-Verlag GmbH Germany, part of Springer Nature 2022

Correction to: Environmental Science and Pollution Research https://doi.org/10.1007/s11356-021-17750-6

Correct presentation of Equation 3 is shown in this paper.

$L=100 \times \sum_{i=1}^{n} B_{i} \times C_{i}$

The Original article has been corrected.

Publisher's Note Springer Nature remains neutral with regard to jurisdictional claims in published maps and institutional affiliations.

The original article can be found online at https://doi.org/10.1007/ s11356-021-17750-6.

Haijun Wang

landgiswhj@163.com

1 School of Resource and Environmental Science,

Wuhan University, 129 Luoyu Road, Wuhan 430079,

People's Republic of China

2 Key Laboratory of Geographic Information System of MOE, Wuhan University, Wuhan 430079, China 